\title{
An insight into Alzheimer's disease and its on-setting novel genes
}

\author{
Jaanaky Vigneswaran', Sivaloganathan Anogh Muthukumar ${ }^{2}$, Mohamed Shafras $^{3}$ and Geetika Pant ${ }^{4^{*}}$ (D)
}

\begin{abstract}
According to the World Health Organisation, as of 2019, globally around 50 million people suffer from dementia, with approximately another 10 million getting added to the list every year, wherein Alzheimer's disease (AD) stands responsible for almost a whopping 60-70\% for the existing number of cases. Alzheimer's disease is one of the progressive, cognitive-declining, age-dependent, neurodegenerative diseases which is distinguished by histopathological symptoms, such as formation of amyloid plaque, senile plaque, neurofibrillary tangles, etc. Majorly four vital transcripts are identified in the AD complications which include Amyloid precursor protein (APP), Apolipoprotein E (ApoE), and two multi-pass transmembrane domain proteins-Presenilin 1 and 2. In addition, the formation of the abnormal filaments such as amyloid beta $(A B)$ and tau and their tangling with some necessary factors contributing to the formation of plaques, neuroinflammation, and apoptosis which in turn leads to the emergence of AD. Although multiple molecular mechanisms have been elucidated so far, they are still counted as hypotheses ending with neuronal death on the basal forebrain and hippocampal area which results in AD. This review article is aimed at addressing the overview of the molecular mechanisms surrounding $A D$ and the functional forms of the genes associated with it.
\end{abstract}

Keywords: Alzheimer's disease, Amyloid beta, ApoE, Presenilin, Mutation, Neuro-degeneration

\section{Introduction}

In the scientific world, scientists are on a constant lookout for an invisible stature to find a cure for unknown complications. These unseen patterns manifest in an organism's life as diseases and are uncontrolled by deviating various cascades in the cellular-biological systems. One such abnormality in humans, identified as Alzheimer's disease (AD), is the most common irreversible, progressive, neurodegenerative disease characterised by a gradual loss of memory and cognitive skills. The above characteristics of disease conditions are accompanied with the appearance of shrinking of total brain size, declining of neural connectivity that gradually leads down to brain cell death with memory loss and dementia, in the final stages. According to the World Health Organisation, more than 55 million people live with dementia,

\footnotetext{
*Correspondence: way2geetika@gmail.com

${ }^{4}$ Department of Biotechnology \& Genetics, M S Ramaiah College of Arts,

Science \& Commerce, Bengaluru, Karnataka 560054, India

Full list of author information is available at the end of the article
}

with approximately another 10 million getting added to the list every year [1]. Current occurrence numbers estimate that an excess of 150 million people may be hit with dementia by 2050, with $\mathrm{AD}$ rating as its primary cause [2, 3]. Neuropsychologists worldwide face major hurdles to understand the cognitive and behavioural manifestations of dementia and their relationship to brain cells.

The ubiquity of $\mathrm{AD}$ in aging communities along with the shortage of a well-defined cure poses it as one of the greatest hurdles of current times. Mostly, the majority of $\mathrm{AD}$ cases that come forth are sporadic Alzheimer's disease (SAD), where aging features as the foremost important risk factor. In a nutshell, it has been observed that reaching 85 years of age heightens the incidence of developing the disease by a significant $20 \%$ [2]. In November 1901, AD was discovered when Auguste D, a 51-yearold patient, was admitted to the Frankfurt Hospital due to dynamic memory misfortune, central manifestations, delusion and mind flights. After her demise in 1906, her cerebrum was sent to Munich for subsequent medical 
examination, where Alzheimer's-associated abnormalities were assessed using the silver staining technique test [4].

On 3rd November, 1906, at the 37th gathering of the Society of Southwest German Psychiatrists in Tubingen, Germany, Alois Alzheimer introduced the clinical and neuropathological characteristics of this disorder. Furthermore, the molecular analyses of the plaque deposits initiated the distinguishing proof of the significant segments causing gene defects in AD. In the late 1980s, with the genetic linkage analysis of AD-affected families, the gene Amyloid Precursor Protein (APP) along with its location in the 21st chromosome was identified. It was found to be the first missense mutation in the APP gene located at the 717th position of valine that was replaced by isoleucine and glycine, resulting in the change of the 46th amino acid of the amyloid protein. Furthermore, it was found in a Dutch family with hereditary cerebral amyloidosis and haemorrhage, the substitution of the glutamic acid by glutamine resulted in E22Q in Amyloid beta $(A \beta)$ protein. This provided the very primary relationship between the amyloid deposition and the APP gene [5].

It is suggested that an altered $A \beta$ metabolism, which involves both production and/or clearance, results in the accumulation of yet-to-be-defined toxic $A \beta$ aggregation in the brain. The accumulation of toxic $A \beta$ for 20 years prior to disease diagnosis, triggers molecular and cellular activities that bring out the intracellular accumulation of hyperphosphorylated tau in neurofibrillary tangles (NFTs), Tau pathology, followed by activation of microand astroglia-inducing chronic neuroinflammation, neuronal dysfunction and subsequent neurodegeneration [6-8].

A host of varied factors are connected with the etiology of AD and associated dementias. They include age, vascular disorders, stroke, infection, diabetes, inflammation, hearing loss, the blood-brain barrier, synaptic, mitochondrial and innate immune system dysfunction, dysfunction of the meningeal lymphatic system, protein misfolding, some environmental and multiple genetic factors [9-11].

Based upon clinical trials and findings based on longterm research, $\mathrm{AD}$ is generally classified into two types: sporadic and familial. In most cases, AD does not run in family trees and this is termed as sporadic, since it has no precise cycle among the family members and relatives. SAD is caused mainly due to an unexplained mixture of our lifestyle, surroundings and the genes that we carry. On the other hand, familial Alzheimer's disease (FAD) is strictly hereditary i.e. it passes down from one generation to the other. FAD is caused due to the inheritance of the dominant autosomal mutations in genes, such as
APP, Presenilin (PSEN) [12]. Even after much research in this field, AD lacks the distinctive difference from Parkinson's disease, Huntington's disease and amyotrophic lateral sclerosis. With the progression of $\mathrm{AD}$, an increased extent of oxidative stress (OS) is determined to upregulate the cellular mediators of the immune system. This can lead to the excessive production of proinflammatory molecules, and also inflammation in the brain [13].

\section{Molecular events in $A D$}

The underlying mechanism in any biological event helps us to distinguish normal conditions from pathological ones. This has triggered a need to study the basic cellular and molecular events underlying the specific disease for better diagnosis. AD entails intraneuronal deposits of NFTs and extracellular accumulation of $A \beta$ plaques [13$15]$. In case of $A D$, there are four known proteins that are found to be highly associated in system-based disorder. These are APP, Apolipoprotein E (ApoE) and two novel seven-transmembrane domain (TMD) proteins called Prenisilin-1 and 2. Genetics has furnished valuable clues regarding the genesis of the disease by disclosing deterministic genes-Presenilins (PSENs) and APP. Hence, a thorough understanding about the mutations and alterations in related genes, study of Tau pathology and neuroinflammation will give greater insights on revealing the onset of disease.

\section{APP and amyloid beta}

The studies conducted by Haapasalo et al., revealed that the $\gamma$-secretase is a proteolytic assemblage of four integral membrane proteins that performs hydrolysis within the lipid bilayer, processing the TMD of more than 90 known substrates $[16,17]$. $\gamma$-Secretase is classified as an intra-membrane aspartyl-protease which catalyses the final step in the regulated intra-membrane proteolysis of a considerable number of single-span type-1 transmembrane proteins. Hence, with such a multi diverse nature they are also known as "the proteasome of the membrane" [18]. The most large-scale studied substrates are the amyloid- $\beta$ precursor protein and the NOTCH receptors [19].

APP is one of the transmembrane glycoproteins which in turn forms the 40-42 amino acid (AA) long $\mathrm{A} \beta$ protein and is responsible for the plaque formation and cerebrovascular deposition during AD [20]. APP gene has 19 coding regions in its complete sequence. However, due to alternative splicing of APP, there results three significant isoforms viz. $751 \mathrm{AA}, 770 \mathrm{AA}$, and $695 \mathrm{AA}$-, wherein the 751 (predominant variant, except for neurons) and 770 isomers are $\mathrm{N}$-terminal, which inhibits the action of the protein-degrading enzymes with their Kunitz domain found mainly in neural and non-neural cells. In 
addition, 695 AA isoform is the predominant transcript mostly found in neurons in large amounts and subjected to axonal transport and transcytosis [21]. The APP gene contains 19 exons, $170 \mathrm{~kb}$ end to end. The alternative splicing of exons 1 to $13,13 \mathrm{a}$, and 14 to 18 results in the isoforms. A part of isoform 695 is produced by the alternative splicing of exons 1-6, 9-18, excluding 13a, and APP 751 by exons $1-7,9-18$, excluding 13 a. APP 770 is exons $1-18$, excluding 13 a. The $\beta$-amyloid protein was reported to be encoded by 16 and 17 neurons (Fig. 1) [22]; however, according to the latest National Center for Biotechnology Information (NCBI) updates, it has been found to have 20 exons. In one such specific case, involving the APP, complex Trans membrane domain cleavage to the amyloid $\beta$-peptide $(\mathrm{A} \beta)$ by the means of $\gamma$-secretase is aberrant in dominantly inherited, early-onset FAD [23]

In addition to molecular basis of the APP gene, the ordinary cleavage of the APP gives a soluble Amyloid precursor protein $\left(\mathrm{APP}_{\mathrm{s}}\right)$ of about 90-100 Dalton [24] which appears to be involved in functions such as inducing cell proliferation, acting as an autocrine factor, increasing adhesion and stimulation of the neuronal outgrowth for the nerve growth hormone (Fig. 2). Besides, $\mathrm{APP}_{\mathrm{s}}$ can also increase the conductance of the potassium ion channels and increase the activity of MAP kinase in overall cascade [25]. As a protein, $A \beta$ has $\mathrm{N}$ and $\mathrm{C}$ terminals, where the $\mathrm{N}$-terminal is found in the extracellular region of the APP, which is 28 AA from the transmembrane region, and $\mathrm{C}$-terminal is located inside the transmembrane. The enzymes $\beta$-secretase and $y$-secretase are responsible for the cleavage to form the $\mathrm{N}$ and $\mathrm{C}$ terminals, respectively. The $\alpha$-secretase cleaves between the residues 16 and 17 and precludes the amyloid formation.
Therefore, the $A \beta$ can be in 40 or 42 AA long chain, where the $42 \mathrm{AA}$ chain is most likely to be deposited [26]. The 3-D structure of the amyloid fibril is as such where 1-17 AA are disordered, 18-42 forms a b-strand-turn-b stand motif which two parallel $b$ sheets formed by residues of 18-26 and 31-42 AA [27].

The function of the APP was unknown for a very long time and its study initiated with the use of knockout mice. The experimental model had no problem in its prenatal period but when it developed into an adult, there was a weight loss by 15 to 20 percent and the ability for locomotion became poor, with motor inability of the forelimb also observed. However, the screening results of the brain showed only diffusive reactive gliosis, with no degeneration at all. Another mouse knocked out was due to exon 2 of the APP gene and it showed corpus callosum getting older coupled with cognitive impairment conditions $[28,29]$.

Drosophila melanogaster (Fruit fly) and Caenorhabditis elegans (Round worm) were found with the APP homologues. Results showed that when the APPs were knocked out, it left a tremendous effect on their behaviour, hinting that the function of APP is conserved in evolution [30, 31]. This clarifies that, without missense changes, the onset of AD can be caused by the duplication of the APP gene [32]. One additional factor named $A \beta$ fibrils can also cause the malady state, while if it is in the non-fibrillar amorphous form, it cannot be neurotoxic [33]. The formation of the $A \beta$ occurs in two steps: primary seeding of aggregate and then the deposition of the peptide [34]. There are several factors that can adhere to the amyloid fibril and increase its neurotoxicity by increasing its aggregation. Some of them are ApoE, heavy

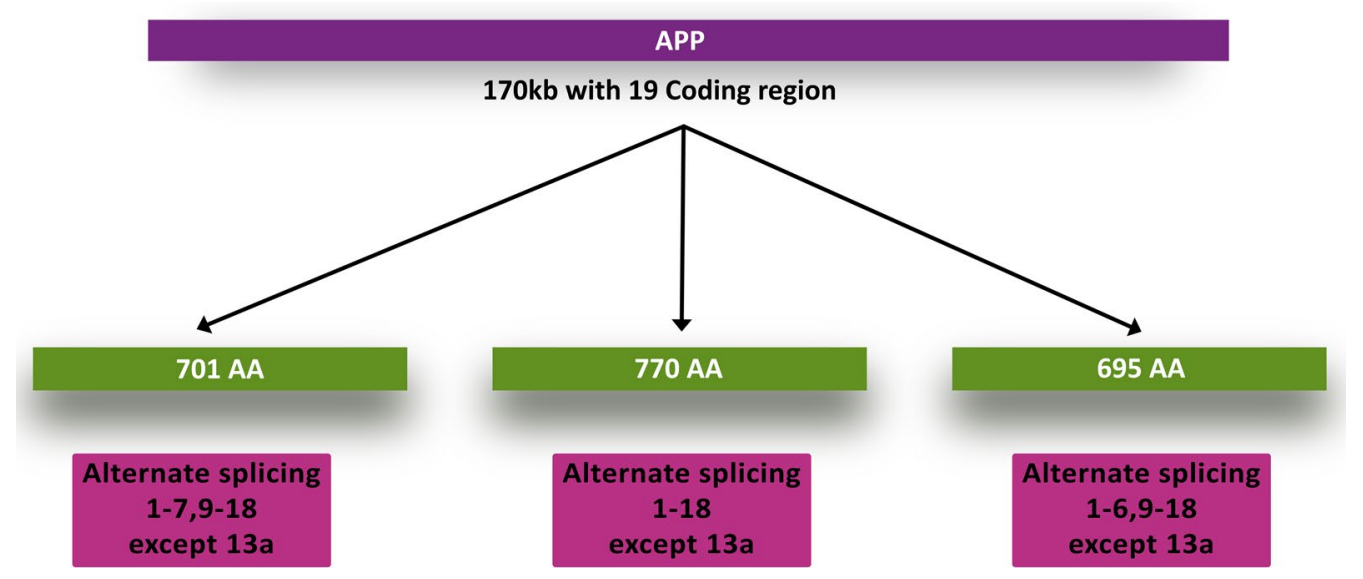

Fig. 1 Alternative splicing of APP mRNA to produce 3 different isoforms of APP protein. The above diagram shows how alternative splicing of same amyloid precursor protein (APP) can produce different isoform of APP protein. The APP gene contains 19 exons, $170 \mathrm{~kb}$ end to end. The alternative splicing of exons 1 to 13,13a, and 14 to 18 results in the isoforms. The isoform 695 is produced by the alternative splicing of exons 1-6, 9-18, excluding 13a, and APP 751 by exons 1-7, 9-18, excluding 13a. APP 770 is exons 1-18, excluding 13a 


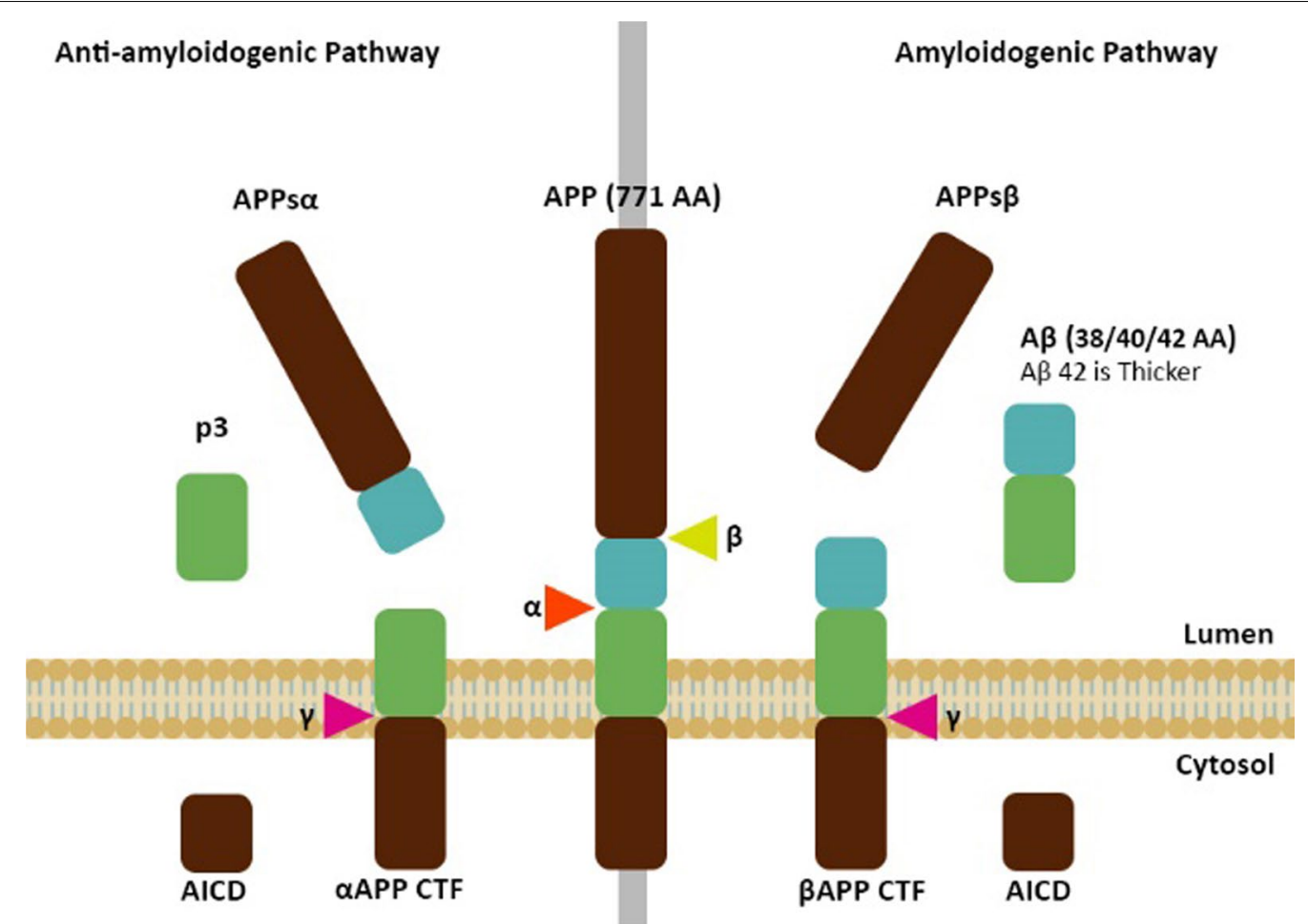

Fig. 2 Amyloid precursor (APP) processing pathway. This diagram shows the proteolysis of Amyloid-beta precursor protein (APP) by the enzymes $\beta$-secretase and $\gamma$-secretase which are responsible for formation of the $N$ and $C$ terminals, respectively. The $a$-secretase cleaves between the residues 16 and 17 and prohibits the amyloid formation. Therefore, the amyloid- $\beta$ can be in 40 or 42 amino acid long chain where the 42 amino acid chain is most likely to be deposited

metals, such as zinc and aluminium, heparin sulphate proteoglycan [35, 36]. In other cases, oxidation can also increase the aggregation of $\mathrm{A} \beta$ by peptide cross-linkage [37]. As the amyloidogenic peptides are toxic to neuronal cells, it can also cause neurodegeneration and apoptosis directly. $A \beta$-associated neurotoxicity can be caused by excitatory AA, glucose deprivation and OS $[38,39]$.

Making it more interesting, the density of the plaque does not tell us exactly about the severity of dementia. The number of NFTs and cortical synapsis loss can give a clear picture rather than plaques. Price et al. reported these synapsis losses and the onset of endosomal-lysosomal enzymes which can occur even in the absence of plaques [40]. So far, numerous pathogenic variants are found in APP [41]. The Flemish mutation, such as the APP duplication, leads to a comparatively late onset of FAD, especially in the mid-fifties. When the variant exerts on the gamma secretase-mediated processing of the segment APP c99, it could explain the earlier onset of AD [12]. The Swedish variant is one among the special as it is located outside the APP c99 fragment and still induces the onset by increasing the amount of $\beta$-secretase which eventually mediates the $A \beta$ production [42, 43]. Apart from the Swedish variants, $\mathrm{D} 678 \mathrm{H}, \mathrm{E} 682 \mathrm{~K}, \mathrm{~K} 687 \mathrm{~N}$ and $\mathrm{A} 692 \mathrm{G}$ also induce the onset of disease by boosting the $\beta$-secretase production $[44,45]$. Some more variants such as I716F, T714I and V717F are more aggressive as they have caused the onset in ages of 31,34 and 37 , respectively, by producing longer $A \beta$ chains while harming $A \beta[26,46]$. Mutations can also directly increase the aggregation rather than affecting indirectly [47]. The contribution of neuroinflammatory processes (particularly, microgliaassociated) to disease development is strengthened using latest genome-wide association studies (GWAS), and the elucidation of cellular and molecular relationships between amyloid, glia activation and neuroinflammation, is presently the most active area of intense research. [48].

Amidst the failure of the amyloid approach, there are rising statistics on the role of vascular, mitochondrial and synaptic network dysfunction. In addition, infection, diabetes, sleep patterns, hearing loss, gut microbiome and neuroinflammation/ innate immune serving as dementia targets are driving studies in novel horizons reinforced through recent discoveries on the genetic, 
omics and systems biology, associated with $\mathrm{AD} /$ dementia [10].

\section{$A D$ and neuroinflammation}

With studies on aggregate formation in AD, it leaves us a hint that there is a correlation between nervous system and immune system. Understanding the interaction between the nervous and immune systems in $\mathrm{AD}$ can help to achieve delay or prevent the prolonged disorder. When a pathological trigger is caused in the brain (neuronal death or aggregation of protein), the response is detected by the Pattern-Recognition Receptors in microglia, which is further recognised by danger-associated molecular patterns or pathogen-associated molecular patterns. Furthermore, the cascade of events induces the microglia which is the resident phagocyte of the brain that extends their processes to the site of injury and move to the lesion, where an innate immune response gets initiated. Soon after the pathological trigger is initiated, the microglia gets activated and changes into an amoeboid-shaped morphology. In case of $\mathrm{AD}$, microglia acquire M1 and M2 types of macrophages where the former plays a defensive role, and the latter helps in promoting tissue repair and angiogenesis. The M1 macrophages are more functioning than the M2 phenotype in case of $\mathrm{AD}$ [49]. The microglia then joins with soluble $A \beta$ and amyloid fibrils through the cell surface receptors, such as SCARA1, CD14, CG36, CD47, $\alpha 6 \beta 1$ integrin and Tolllike receptors (TLR2, TLR4, TLR6, and TLR9) [50]. However, the binding of $A \beta$ with cell surface receptors results in the activation of microglia (Fig. 3).

Microglial activations have two effects on AD. First, activation of microglia, leading to the reduction of $A \beta$ accumulation by increasing its phagocytosis, clearance and degradation. Protein $A \beta$ which is a tough structure for proteases, is degraded by enzymes, such as neprilysin and insulin-degrading enzyme (IDE), preventing the formation of amyloid plaques in the brain. The microglia then starts to engulf the $A \beta$ fibril and undergoes an endo-lysosomal pathway. Second, prolonged microglia activation leads to the release of pro-cytokines, which induces a pro-inflammatory cascade. The formation of plaques occur due to the inefficient clearance by lack of microglial activity resulting in increased concentration of cytokine levels by the repression of the $A \beta$ phagocytosis receptors [51, 52]. However, above all, what makes elderly people more prone to $\mathrm{AD}$ is a phenomenon known as priming. Priming is defined as an increase in microglial sensitivity to inflammatory provocation and a subsequent in neurodegeneration, with the advancement in age. The defensive mechanism of the host and neuroprotection are shielded up and the endogenous ligands are downregulated with increasing age [53]. Above all, treating
$\mathrm{AD} /$ Dementia by employing advanced therapeutic strategies on well-known model systems such as engineered cell lines, transgenic animals and humans has been in research limelight for over four decades [54]. Thus, AD can be summed up as a gradual neurological disorder with hippocampal and cortical atrophy, synaptic losses and neurodegeneration [55].

\section{ApoE and Tau pathology Apolipoprotein E}

The very common apolipoprotein in the brain which is synthesized mainly by astrocytes and microglia is ApoE [56] and is the second on-setting gene in AD associated disorder. The ApoE gene is situated on chromosome 19 with three major alleles-E2, E3 and E4. Among them, ApoE3 is the most widespread allele. The most important function of ApoE is to traffic the phospholipid and cholesterol by getting lipidated through the action of ATP-binding cassette transporter ABCA1 and accessory proteins [57]. The status of the lipidation of ApoE influences its binding pattern with $A \beta$ [58]. According to studies with transgenic mice, isoforms of the ApoE have shown their specific effects on the nature of deposition and its magnitude of infection. It can also function by forming abnormal fibrils when the lipidation status changes, followed by deposition of plaques.

Studies conducted by Iwata et al. revealed that $A \beta$ is cleared by degrading it proteolytically by neprilysin and IDE which is secreted by microglia and astrocyte [59]. Consequently, when the genes for $\mathrm{A} \beta$ and IDE genes were inactivated and the protease inhibitors were used, it resulted in increased $A \beta$ in the brain with a gradual increase in plaque formation $[60,61]$ and when the genes were over-expressed, it showed antagonistic behaviour (decrease in $A \beta$ ) [62]. Therefore, the disease pathology can be lessened by increasing the lipidated form of ApoE. Regulation of Liver $X$ Receptor transcriptional activity can regulate the ApoE level in the brain and increase the lipidated form of ApoE which can decrease disease pathology [63].

\section{Tau pathology}

Tau is a neuronal microtubule-stabilising protein. Tau is well-approved as an important component in the putative genesis of $\mathrm{AD}$ and being a prime aspect of NFTs $[64,65]$. The six isoforms of tau range in length from 352 to $441 \mathrm{AA}$ and are encoded with the aid of 11 exons, of which exons 2, 3 and 10 may be instead spliced to generate six central nervous system isoforms [66], which have multiple sites for acetylation, methylation, O-glycosylation, phosphorylation, ubiquitination, Small Ubiquitin-like Modification (SUMOylation) and proteolytic cleavage. Normally, ApoE binds with 


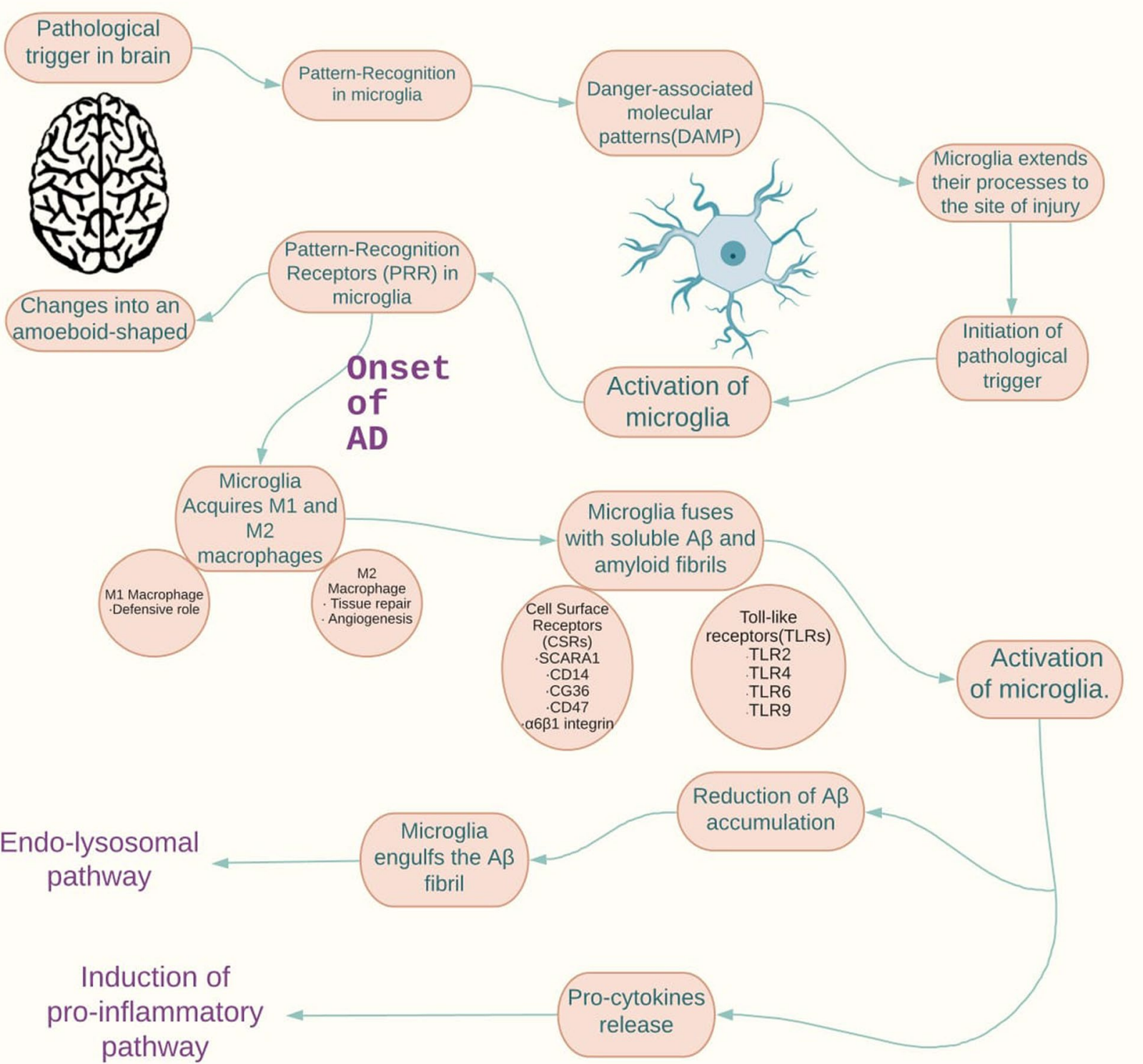

Fig. 3 Pathological interplay between microglia and macrophages in AD. Pathological trigger is detected by Pattern-Recognition Receptors (PRRs) in microglia recognized by pathogen-associated molecular patterns (PAMPs) or danger-associated molecular patterns (DAMPs). The protein cascade induces microglia to initiate immune response at the injury site by acquiring $M 1$ and $M 2$ macrophages. Furthermore, microglia fuse with soluble $A \beta$ through cell surface receptors (CSRs)/ Toll-like receptors (TLRs) and amyloid fibrils resulting in its activation and leading to phagocytosis, clearance and degradation of $A \beta$. The engulfment of $A \beta$ turn on the endo-lysosomal pathway in microglia. On the other hand, prolonged activation of microglia leads to release of pro-cytokines that induces pro-inflammatory cascade.

non-phosphorylated tau (p-tau) microtubule-associated protein where it helps to reduce the hyperphophorylation of tau. ApoE3 mostly tends to join tau protein, even more that the isoform ApoE4. When ApoE does not associate with Tau, it undergoes hyperphosphorylation wherein it loses its capability to associate with the microtubule [67, 68]. Thus, it leads to the distortion of the cytoskeleton and formation of a neurofibrillary tangle (NFT) in the neuronal somata and neurite thread in the neuronal projections, after aggregation. The neurite plaque which is a combination of $A \beta$ and hyperphosphorylated tau, is the unique identification of $\mathrm{AD}$ [69].

In 1991, Braak classified AD status into six stages based on the brain region that has the NFT. Braak stage 1-NFT and neurite tangles (NT) are present in the transentorhinal region, stage 2 in the entorhinal 
region, stage 3 in the hippocampus and temporaloccipital gyrus, stage 4 in the temporal cortex, stage 5 in the parietal cortex and stage 6 in the occipital cortex [70]. According to the recent notation, however, NFT, NT and pre-tangles are also found in Substantia Niagara, Locus Coeruleus (LC), and dorso-motor nucleus of the vagus nerve $(\mathrm{dmX})$ that have been detected using immunohistochemical methods using specific antibodies. Furthermore, research after the post-mortem revealed that the AD possibly begins from the $\mathrm{LC}$ which led to the revision of the Braak's stages [71].

Once the tau is hyperphosphorylated, the major part is secreted in the form of free soluble and minority as small membrane-bound vesicles [72]. When it is secreted in the vesicle free form, cell surface heparan sulphate proteoglycans support tau secretion by increasing the penetration through the membrane. Conceptually, it was well-expressed in the experiment with over-expressed tau in N2A neuroblastoma cell line [73]. The N-Myconcogene (MIC) neuroblastoma which expresses wild-type human tau after induction expressed both the free-form and the vesicle form [74], while the COS-7 and human embryonic kidney (HEK) showed the release of tau in macrovesicle even in the absence of cell death [75]. Pathological tau undergoes cell-cell transmission starting from the LC and penetrating across the whole brain including the Cerebrospinal Fluid (CSF). The hyperphosphorylated tau which is detached from the microtubule is taken to the next neuron and it starts misfolding the normal tau in the cytosol of the recipient cell and forms the paired helical filaments (NFT) [76]. Therefore, the loss of NFT affected neurons and creates a gap in the neural circuit which results in the effect in memory and cognitive functions. Tau secretion is also found in the normal healthy human CSF and interstitial fluid but what makes them a biomarker of $\mathrm{AD}$ is particularly their concentration and phosphorylation rate. In $\mathrm{AD}$, tau was hyperphosphorylated in all the twenty epitopes of p-tau as diagnosed during the post-mortem of frontal cortex of an AD patient by immunoblots using commercially available antibodies against twenty different phosphor-epitopes of tau [77].

During disease management, detecting total tau and $\mathrm{p}$-tau is very helpful in diagnosing $\mathrm{AD}$ and differentiating from other neurodegenerative diseases. Tau phophorylation at Threonine 231 differentiates AD from frontotemporal dementia and Serine 181 from Lewy bodies [78]. As per the recent study conducted by Muynck et al., 2021 it was found that microglial differentially expressed genes and astrocyte gene CDK2AP1plays a central role in AD pathogenesis. This was corelated with the development of $\mathrm{AD}$ at the immune system level playing a key part in the etiology [79].

\section{Presenilins (PSENs)}

PSENs are two autosomal dominant genes which encode two multi-pass proteins Presenilin 1 (PS1) and Presenilin 2 (PS2). They comprise of catalytic sub-structure of membrane-embedded $\gamma$-secretase complexes that function as proteolytic switches regulating key cell signalling cascade and found to be connected to signalling from the Notch family of cell-surface receptors [17]. They have been identified in the 14th chromosome (14q24.3) and 1st chromosome (1q42.2), respectively, [80]. They take part in neuronal differentiation and synaptogenesis where they help in learning and memory. The PS1 was found to be linked with the post-synaptic N-acetyl-D-aspartic acid receptor where it helps in facilitating a proper synaptic delivery and localisations of N-methyl-D-aspartate (NMDRs) [81]. It was reported to interact with Rab11, a small GTPase which is involved in the transport of vesicles [82] and also appeared to be a central component in the calcium homeostasis [83, 84]. PS1 and PS2 are nine TMD and three TMD proteins, respectively, forwarding both their terminals into the cytoplasm. PS1 is the catalytic subunit of the intramembranous aspartyl protease gamma-secretase which cuts the APP and results in variable length. Production of longer chain $A \beta$ in turn increases the aggregation, leading to AD that supports the amyloid cascade hypothesis [85]. The PS1 and PS2 genes encode transmembrane proteins that join together with Nicastrin, Anterior Pharynx-defective 1, and Presenilin Enhancer 2 into a tetrameric complex with a 1:1:1:1 stoichiometry and generate a pentameric activated protease called gamma secretase after undergoing autoproteolytic activation during the assembly. Furthermore, both $\mathrm{C}$ and $\mathrm{N}$ terminal of the Prenesilin 1 and 2 aspartyl residues combine to form the central hydrolytic centre of the complex [86, 87]. Studies have shown more than three hundred mutations occur in PSEN1 and fifty six mutations in PSEN2. Most of the PSEN1 mutations are pathogenic, while some PSEN2 are disease causing. Till 2019, almost 235 pathogenic PSEN1 mutations have been recorded [88]. Mutations in the PSEN1 gene cause the earliest onset of the disease which initiates from 28 to 60 years. Mutations in the PSEN2 gene were found in the German familial AD and in the Volga Valley in Russia with varying on-setting ages (35-82) [89].

The exact number of 138 mutations in the PSEN1 have been analysed and it showed that almost ninety percent of the mutations lead to an increase in the ratio between $A \beta 42 / A \beta 40[80,90]$. When all the known pathogenic and four non-pathogenic mutations were studied using 21 different computational methods, it showed that the alterations involving the AA proline and glycine along with charged residues, attribute to the disease on-setting. PSEN1 mutations 
tend to disturb the conformational integrity and most likely, lead to the open state of gamma-secretase. These results further lead to lesser retention time, trimming and increased production of $\mathrm{A} \beta_{42}$ [91].

In 2010, a strikingly different earlier onset case was reported in PSEN2 with a frameshift mutation wherein two base pair deletions were found (PSEN2 c.342-343 del GA, p.K115Efs*1). After a targeted exome screening, a second earlier onset with the same variant was found. Two of them were evaluated together and it stated that the PSEN2 K115Efs* 1 fibroblasts secrete less $A \beta_{1-40}$ due to abnormal gamma-secretase and it showed alternatively spliced PSEN2 products in the patient's brain. The data suggests that the PSEN2 K115Efs*1 is more likely to be a pathogenic variant [92].

The PSEN1's structure is called as a gate-membrane structure where the transmembrane 5 and 6 regions build the gate, and the exon 9 loop region makes the plug. A mature PSEN1 undergoes endoproteolytic cleavage by an unplugging mechanism. When the mutations happen in PSEN1, it can disrupt the way gate-plug functions, reducing access to the substrate and inaccurate cleavage. When the histidine is replaced by lysine in TM5 and 6, even if it gives a normal structure to the gamma-secretase, the activity of the enzyme was defective [93]. Recently, many studies found non-canonical (non-gamma-secretase related) roles of presenilins in $\mathrm{AD}$, such as influencing $\mathrm{Ca}^{2+}$ signalling pathway, autophagy, cellular oxidative stress, regulating intracellular endoplasmic reticulum (ER) $\mathrm{Ca}^{2+}$ channels, i.e., inositol 1,4,5-triphosphate receptors and ryanodine receptors [94].

A high level of reactive oxygen species (ROS) and mitochondrial malfunctions has been observed in most of the neurodegenerative disease $[95,96]$. When the ER-mitochondria signalling were reduced, the ROS levels were also found to be decreased. While elevated ER-mt $\mathrm{Ca}^{2+}$ signalling increases oxidative phosphorylation resulting in increase of ROS levels. It was also noted that higher ROS levels caused cellular damage to neurons by destroying their lipids, proteins and DNA.

The The Clustered regularly interspaced short palindromic repeats/ CRISPR associated protein 9 (CRISPR/ Cas9) genome editing tool has attracted many researchers owing to its direct treatment approach in management and curing of AD. This precise and recent technology with interspaced short palindromic repeats/ CRISPR associated proteins 9 system is emerging as one of the most promising tools in treating neurodegenerative diseases, such as AD. It can not only alter the SAD and FAD, but also the $A \beta$ metabolism irrespective of genetic factors. As a result, CRISPR/Cas9 technology could correct increased $\mathrm{Ab}$ production or mutations in APP, PSEN-1, and PSEN-2, since these genes in turn cause mutations in FAD [97].

\section{GWAS and associated AD-risk loci}

GWAS have been instrumental in identifying genetic loci associated with AD. With the advent of wholegenome sequencing (WGS), genome-wide analyses to identify rare variants responsible for $\mathrm{AD}$ pathogenesis is now possible. A previous study performed a genomewide association meta-analysis of clinically diagnosed late-onset Alzheimer's disease (LOAD) and identified five new genome-wide loci: IQCK, ACE, ADAM10, ADAMTS1, and WWOX [48]. Another study performed on de novo early-onset Alzheimer's disease (EOAD) samples by next-generation sequencing confirmed three missense mutations in PSEN1 (T119I, G209A, and G417A) and one in PSEN2 (H169N). Besides, 67 missense mutations in genes implicated in LOAD were also identified having roles in cholesterol transport, inflammatory response and $\beta$-amyloid modulation. 70 other additional novel and missense variants in genes, such as MAPT, GRN, CSF1R and PRNP, known to cause neurodegenerative diseases were also identified [98]. A single-variant and spatial clustering-based testing on rare variants further identified 13 new AD candidates implicating the following genes: FNBP1L, SEL1L, LINC00298, PRKCH, C15ORF41, C2CD3, KIF2A, APC, LHX9, NALCN, CTNNA2, SYTL3 and CLSTN2. In contrast to the common AD-associated variants, these genes have roles in synaptic function rather than innate immunity and amyloid processing [99]. GWAS on a large Korean population identified nine single nucleotide polymorphisms (SNPs) on chromosome 7 , four of which were associated with a decreased risk of A $\beta$ positivity (rs73375428, rs2903923, rs3828947, and rs11983537). rs73375428, interestingly, was found to be associated with decreased expression levels of FGL2 in the brain [100]. WGS on DNA from AD patient blood samples and elderly controls of Korean ethnicity who were also APOE $\varepsilon 4$ carriers and customized $\mathrm{AD}$ chip data of an independent set of $\mathrm{AD}$ patients and elderly controls of the same ethnicity, regardless of their APOE $\varepsilon 4$ allele status identified SNPs rs 1890078 and rs12594991 in SORCS1 and CHD2 genes, respectively, as novel genetic variants in APOE $\varepsilon 4$ carriers in the Korean population. This study also identified nine novel variants rare in Europeans but common in East Asians [101]. Whole Exome Sequencing (WES) study from Chinese AD patient samples identified various novel variants in genes implicated in a multitude of cellular and physiological processes. Some of the novel variants in previously identified genes were ADAR, AHNAK, APOB, HMCN1, HSPG2, IL16, INPPL1, LRP1, NTN1, RYR1, SORL1, TNC and TNR. Other variants identified with 
indirect links to AD were BAI2, CCDC120, DNAH11, DNAH14, FAT1, FAT4, HTR3B, HUWE1, KMT2C, KMT2D, MATN2, MX2, NLRC4, UBR4 and UNC13B [102]. Six new variants associated with AD risk (near APP, CHRNE, PRKD3/NDUFAF7, PLCG2 and two exonic variants in the SHARPIN gene) were identified in a large genetic association study by merging all available case-control data sets and by-proxy study results. The study also revealed a 4-5.5 year difference in median age at onset of AD in APOE \&4 carriers (assessment by polygenic risk score (PRS) and stratifying by APOE) [103]. Another study assessing the PRS restricted to synapseencoding loci in LOAD predicted that synapse-encoding genes were enriched for LOAD risk-modifying loci. Variants in BIN1, PTK2B, PICALM, APOE (previously identified LOAD loci) and two novel loci, DLG2 and MINK1, involved in glutamate signaling or APP catabolism or tau binding were identified [104]. An integrative proteomewide association study in the brain and blood utilizing Mendelian randomization and Bayesian colocalization identified 7 abundant genes, ACE, ICA1L, TOM1L2, SNX32, EPHX2, CTSH and RTFDC1 as causal in AD. Interestingly, proteins encoded by these genes were mostly expressed on the surface of glutamatergic neurons and astrocytes [105]. An exome-wide association analysis of age-of-onset of AD emphasizing on APOE $\varepsilon 4$ non-carriers identified two novel variants, rs56201815 (variant in ERN1) and rs12373123 (a missense variant in SPPL2C in the MAPT region) along with a rare missense variant, rs144292455 in TACR3 gene. The rs56201815 allele exhibited high expression of ERN1, a key regulator of unfolded protein response (UPR) pathway. The rs12373123 minor allele, on the other hand significantly exhibited high expression of GRN in microglia, and was associated with MAPT expression in astrocytes. This study supported the putative involvement of the UPR/ ER stress in the pathological pathway of AD [106].

GWAS of large cohorts of LOAD identified the ATPBinding Cassette Subfamily A Member 7 gene (ABCA7) as a risk gene. Premature termination codons (PTC) causing loss-of-function of ABCA7 were enriched in LOAD patients. This enrichment of ABCA7 PTC mutations was confirmed in studies involving Belgian $\mathrm{AD}$ patients [107]. A survey studying ABCA7 protein levels in the hippocampus or parietal cortex of healthy or $\mathrm{AD}$ patients showed that individuals with low ABCA7 levels were susceptible and developed $\mathrm{AD}$ at a younger age compared to those with high ABCA7 levels who developed $\mathrm{AD}$ very late, resembling the youngest controls. It is speculated that vulnerable neurons in the brain generate a yet to be identified neurodegenerative lipid that is cleared by ABCA7 [108]. A metabolomics approach studied how ABCA7 haplodeficiency modulates the metabolic profile in mouse brains during acute immune response by peripheral administration of lipopolysaccharide (LPS). Weighted gene co-expression network analysis identified pathways involving glycerophospholipid metabolism, linoleic acid metabolism and $\alpha$-linolenic acid metabolism to be modified. Abca7 heterozygous mice also exhibited increased levels of eicosapentaenoic acid, oleic acid and palmitic acid in the brain upon LPS stimulation [109]. Partial ABCA7 deficiency diminished proinflammatory responses by impairing CD14 expression on acute LPS stimulation in the brain of control or heterozygous $A b c a 7$ knockout mice. The presence of amyloid pathology in heterozygous $A b c a 7$ knockout mice resulted in increased amyloid- $\beta$ (A $\beta)$ accumulation and abnormal endosomal morphology in microglia [110]. A recent study involving Australian patients found that several lipid species, mainly sphingomyelins, cholesterol esters, phosphatidylcholines, phosphatidylethanolamines, phosphatidylinositols and triglycerides (TGs) were dysregulated in $\mathrm{AD}$ patients when compared to their healthy counterparts. They also found FERMT2 and MS4A6A to show a significantly differential association with all lipid classes across disease and control groups. ChE showed differential association with PICALM, SLC24A4 and SORL1; PE with CLU and CR1 and TG with BINI between AD and control groups [111].

Mutations in the sorting receptor-encoding gene SORL1 have been implicated in autosomal-dominant AD. SORL1 variants are known to increase the risk for LOAD. Truncating mutations in SORL1 leads to haploinsufficiency and enlarged endosomes in human neurons. Heterozygous SORL1 mutations results in endosome dysfunction, whereas complete loss of SORL1 leads to defects in lysosome function accompanied by autophagy [112]. SORL1 is also reported to be strongly associated with both sporadic and familial forms of AD. An alternatively spliced transcript of SORL1 (SORL1-38b) encodes a truncated protein that was found to be localized in neuronal dendrites, different from the somatic distribution of transcripts encoding the full-length SORL1 protein (SORL1-fl). Recent studies have shown that SORL1-38b transcript levels were significantly reduced in AD cerebellum, whereas no changes were observed for SORL1$\mathrm{fl}$ [113]. Dysfunctional endosomal recycling is a hallmark of AD. SORL1 haploinsufficiency in young minipigs were found to phenocopy the preclinical in vivo profile of $\mathrm{AD}$ leading to spinal fluid abnormalities in A- $\beta$ and Tau, with no evident neurodegeneration or amyloid plaque formation [114]. Mutations in SORL1 alters the recycling of the APP out of the endosome leading to APP misprocessing. A recent study using human induced pluripotent stem cell derived neurons has shown that endosomal trafficking of the BDNF receptor Tropomyosin-related kinase B, 
and the glutamate receptor subunit AMPA1 (GLUA1) is also hindered by loss of SORL1. On the contrary, endosomal recycling of APP and GLUA1 is augmented upon SORL1 expression. This study establishes SORL1 as a master regulator of retromer-dependent endosomal recycling in neurons [115]. WES in EOAD and LOAD families revealed key SORL1 mutations in both the families. In EOAD, two key changes, T588I and T2134M, whereas in LOAD, A528T and T947M were identified. These mutant variants of SORL1 weaken its interaction with full-length APP, altering levels of A- $\beta$ and impedes APP trafficking [116].

Triggering receptors expressed on myeloid cells 2 (TREM2), a microglia receptor for lipids has been implicated in AD pathogenesis. Disease-associated-microglias are transcriptionally distinct and neurodegenerationspecific microglia and are dependent on TREM2. Singlenucleus RNA sequencing on AD mice models and human patients identified a novel Serpina3 $\mathrm{n}^{+} \mathrm{C} 4 \mathrm{~b}^{+}$reactive oligodendrocyte population in mice. Analysis of human AD patient samples revealed different glial phenotypes with altered signatures in microglia, oligodendrocytes and astrocytes [117]. A variant of the human TREM2, R47H impairs ligand binding and increases $\mathrm{AD}$ risk. It has been shown in mouse models of amyloid $\beta$ (A- $\beta$ ) accumulation that impaired TREM2 function affects microglial response to $A \beta$ plaques and aggravates tissue damage. Conversely, TREM2 overexpression reverts these defects leading to a speculation that TREM2 activation may help AD patients. A recent study administering anti-human TREM2 agonistic monoclonal antibody (mAb), AL002c, in a mouse $A D$ model expressing the $\mathrm{R} 47 \mathrm{H}$ variant resulted in induction of proliferation in $\mathrm{R} 47 \mathrm{H}$-transgenic mice. Furthermore, the study also showed that prolonged administration of AL002c also reduced filamentous plaques and neurite dystrophy [118]. Another study has shown that TREM2 engagement by administering the $\mathrm{mAb}$ hT2AB activates microglia in transgenic mice models that accumulate A- $\beta$ and express TREM $2^{\mathrm{R} 47 \mathrm{H}}$ variant. Disease-associated (DAM), interferon-responsive (IFN$\mathrm{R})$, cycling (Суc-M) and MHC-II expressing (MHC-II) microglia types were all downregulated in TREM2 ${ }^{\mathrm{R} 47 \mathrm{H}_{-}}$ $\mathrm{AD}$ transgenic mice, suggesting that TREM2 ligand interaction is needed for microglia activation. However, a single systemic injection of hT2AB restored Cyc-M, IFN-R, and MHC-II pools in TREM $2{ }^{\mathrm{R} 47 \mathrm{H}}$-AD transgenic mice. In addition, repeated treatment with murinized hT2AB increased chemokine content in TREM $2^{\mathrm{R} 47 \mathrm{H}}$-AD transgenic mice brains, congruent with microglia expansion [119]. Gene expression profiling from microglia differentiated from isogenic, CRISPR-modified TREM2knockout induced pluripotent stem cell lines revealed that TREM2 deletion reduces microglial survival, impairs phagocytosis of key substrates including APOE, and inhibits SDF- $1 \alpha /$ CXCR4-mediated chemotaxis, undermining the response to beta-amyloid plaques in vivo. Single-cell sequencing of xenotransplanted human TREM2 knockout microglia also showed a loss of disease-associated microglial (DAM) responses [120]. Another study demonstrated that amyloid plaque seeding is increased in the absence of functional TREM2 in mice due to reduced phagocytic clearance of amyloid seeds. This increased seeding is associated with reduced microglial clustering around the new plaques. Besides, there was also reduced ApoE association with these plaques. This phenotype is remarkably similar to that observed in brains of $A D$ patients expressing TREM2 coding variants. Furthermore, small animal positron emission tomography (PET) showed enhanced amyloidogenesis in TREM2 loss-offunction mutants at early stages that progressed with aging [121].

ApoE is another major genetic risk modifier for AD. There are three common coding variants of APOE$\mathrm{APOE}^{*} \varepsilon 2, \mathrm{APOE}^{*} \varepsilon 3$ and $\mathrm{APOE}^{*} \varepsilon 4$. Among these three, $\mathrm{APOE} * \varepsilon 4$ increases, whereas $\mathrm{APOE} * 2$ decreases the risk of LOAD compared with APOE* $\varepsilon 3$. There is evidence to suggest that $\mathrm{APOE} * \varepsilon 2$ confers protection against $\mathrm{AD}$ through amyloid- $\beta$ (A- $\beta$ )-dependent and independent mechanisms. In addition, $\mathrm{APOE}^{*} \varepsilon 2$ is termed as a longevity gene, indicating it has a systemic effect on the aging process. $\mathrm{APOE}^{*} \varepsilon 2$ carriers, however are more susceptible to certain cerebrovascular diseases and neurological disorders [122]. APOE2/2 was associated with a low Alzheimer's dementia odds ratios compared to APOE $2 / 3$ and $3 / 3$, and an exceptionally low odds ratio compared to APOE4/4 in a study generating Alzheimer's dementia odds ratios and other findings in clinically and neuropathologically characterized Alzheimer's dementia cases and controls [123]. In a recent study analyzing clinical data sets as well as animal models, it was shown that the association between $A P O E 2$ and longer lifespan was independent of $\mathrm{AD}$ status and its activity could be connected to cholesterol and triglyceride metabolism [124]. A recent study using PET, structural magnetic resonance imaging (MRI) and cognitive testing suggests that the protective effect of the APOE- $\varepsilon 2$ allele against $A D$ is primarily linked to resistance against A- $\beta$ deposition rather than tau pathology [125]. Another study using postmortem brain samples of AD carriers to explain APOE alleleassociated changes in transcriptomes and lipidomes demonstrated significant enrichment in GO terms associated with genes involved in proteasomal degradation and autophagy, unfolded protein response, mitochondrial function and nucleolar modifications of mRNA. Phosphatidylethanolamine, phosphatidic acid and mitochondrial membrane-forming lipids were all significantly 


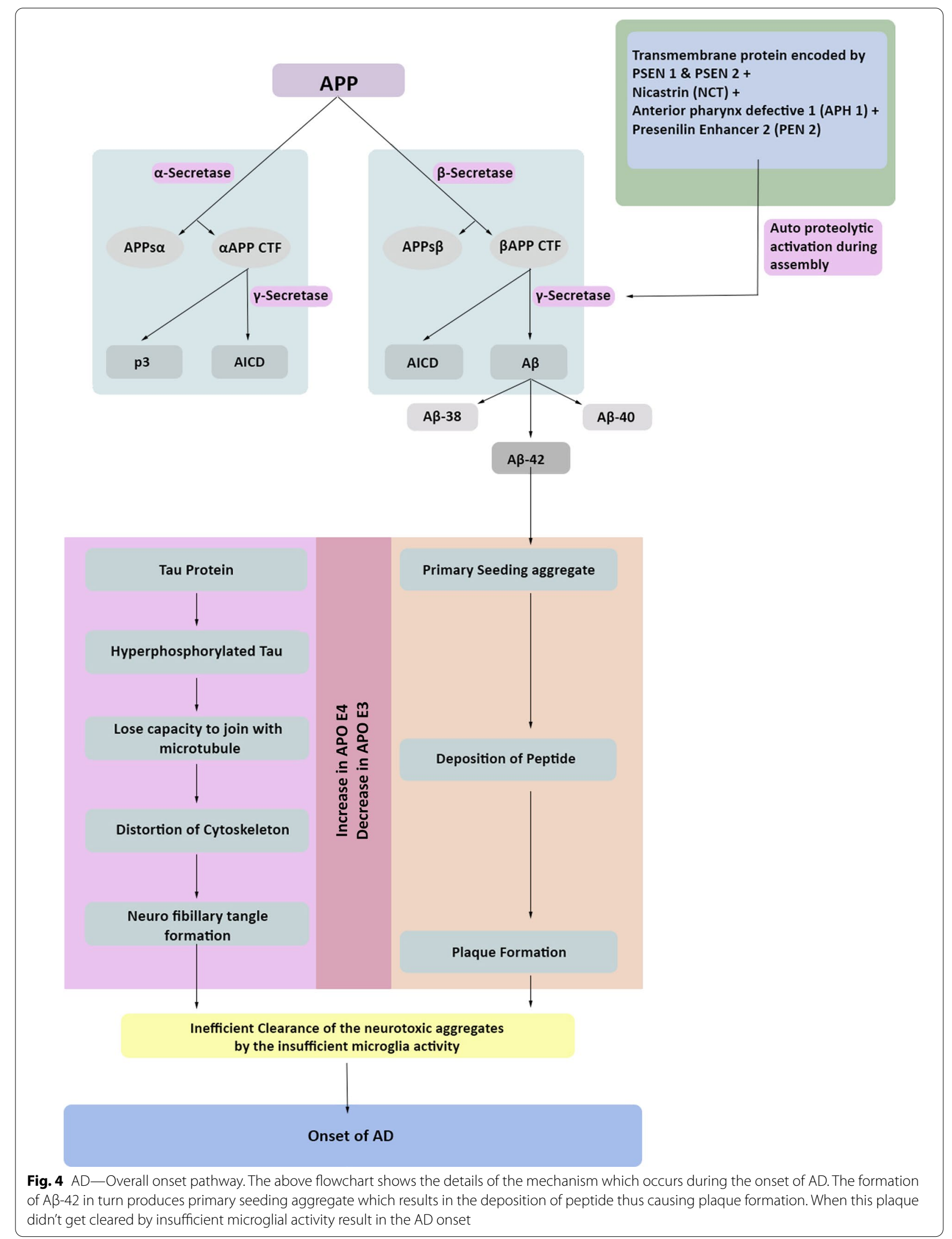


decreased in postmortem brain samples of various AD carriers [126].

$\mathrm{AD}$ is the leading cause of dementia and is set to become the most burdensome disease of this era. The earliest phase of $\mathrm{AD}$ begins with accumulating amyloid $\beta$, that induces the spread of tau pathology. APOE alleles have been identified as the strongest $\mathrm{AD}$-associated genetic risk loci [127]. Some protective mutations such as the rare Ala673Thr Icelandic mutation of APP and another rare Pro522Arg AA change in the PLCG2 gene were found to be associated with prolonged cognitive health and two times reduced risk of $\mathrm{AD}$ in middle-aged individuals $[128,129]$. ApoE has been shown to bind amyloid $\beta$ plaques and the $\mathrm{AD}$-associated genetic variants of TREM2, Arg47His, Arg62His and Asp87Asn, all of these decrease binding of TREM2 to ApoE [130, 131]. Multitude of other proteins linked to genetic risk of AD such as SHIP1, CD2AP, RIN3, BIN1, PLCG2, CASS4, and PTKB2 are speculated to act downstream of ApoE and TREM2 thereby regulating endocytosis, motility, and phagocytosis in microglia.

One recent study employing GWAS meta-analysis identified 3,915 variants that were significantly associated with $\mathrm{AD}$ risk. These variants were spread across 38 independent loci, of which 7 were novel and a functional follow-up of the genomic risk loci further narrowed down AGRN, TNIP1, HAVCR2, TMEM106B, GRN, NTN5 and LILRB2 as the most likely causal genes for these seven novel AD-associated loci [132, 133].

Another large genome-wide association metaanalysis of clinically diagnosed LOAD confirmed five new genome-wide risk loci: IQCK, ACE, ADAM10, ADAMTS1 and WWOX. In addition, fine-mapping of the human leukocyte antigen (HLA) region confirmed the neurological and immune-mediated disease haplotype HLA-DR15 as a risk factor for LOAD. Furthermore, pathway analysis indicates immunity, lipid metabolism, tau binding proteins and APP metabolism pathways to be affected in LOAD [48]. Overall pathway of onset of AD shown in Fig. 4.

\section{Conclusions}

The growing incidence of $\mathrm{AD}$ in conjunction with a dearth of effective treatments, pose of it as one of the major health challenges in current times. AD is caused by a combination of genetic factors, environmental factors and lifestyle which gradually affects the brain over a period of time. Only minimal numbers of cases are reported with specific genetic alterations among which Earlier On-setting $A D$ is significant. The gene mutations in the APP gene, ApoE and Presenilins can pass from parent to offspring in an autosomal dominant pattern. Once the $\mathrm{AD}$ is initiated, it collapses the memory, thinking and reasoning, and social and behavioural aptitudes. The GWAS research has shown multiple pathways with varied time lines of disease progression and clinical manifestations. As the progression of $\mathrm{AD}$ is guided by diverse genes, a significant precise biomarker system at the clinical level is required [134]. This will open the possibilities to evaluate new strategies in treatment at the onset of the disease.

\begin{abstract}
Abbreviations
AD: Alzheimer's disease; APP: Amyloid precursor protein; ApoE: Apolipoprotein E; AB: Amyloid beta; FAD: Familial Alzheimer's disease; SAD: Sporadic Alzheimer's disease; PSEN: Presenilin; AA: Amino acid; APPs: Soluble amyloid precursor protein; OS: Oxidative stress; TMD: Transmembrane domain; IDE: Insulin-degrading enzyme; NCBI: National Center for Biotechnology Information; GWAS: Genome-wide association; NFT: Neurofibrillary tangle; NT: Neurite tangles; LC: Locus Coeruleus; CSF: Cerebrospinal fluid; p-tau: Phosphorylated tau; PS1: Presenilin 1; PS2: Presenilin 2; ER: Endoplasmic reticulum; ROS: Reactive oxygen species; WGS: Whole-genome sequencing; LOAD: Late-onset Alzheimer's disease; EOAD: Early-onset Alzheimer's disease; WES: Whole exome sequencing; PRS: Polygenic risk score; UPR: Unfolded protein response; PTC: Premature termination codons; LPS: Lipopolysaccharide; TGs: Triglycerides; PET: Positron emission tomography; CRISPR/Cas9: The clustered regularly interspaced short palindromic repeats/ CRISPR associated protein 9; SNP: Single nucleotide polymorphisms.
\end{abstract}

\section{Acknowledgements}

Authors are grateful to Mr. Sabyasachi Choudhury for his unceasing support in the editing process of the manuscript.

\section{Authors' contributions}

JV \& SAM contributed to the conception, design of the work, and data acquisition; drafted the work, and approved the submitted version. MS and GP contributed to drafting the work, critically revised the manuscript. All authors read and approved the final manuscript.

\section{Funding}

Not applicable.

Availability of data and materials

Not applicable.

\section{Declarations}

Ethics approval and consent to participate

Not applicable.

\section{Consent for publication}

Not applicable.

\section{Competing interests}

The authors declare that they have no competing interests.

\section{Author details}

${ }^{1}$ Teresian College, University of Mysore, Mysore, Karnataka, India. ${ }^{2}$ Department of Studies in Biochemistry, University of Mysore, Mysore, Karnataka, India. ${ }^{3} \mathrm{Fac}-$ ulty of Applied Sciences, Sabaragamuwa University of Sri Lanka, Belihuloya, Sri Lanka. ${ }^{4}$ Department of Biotechnology \& Genetics, M S Ramaiah College of Arts, Science \& Commerce, Bengaluru, Karnataka 560054, India.

Received: 20 August 2021 Accepted: 19 November 2021

Published online: 29 November 2021 


\section{References}

1. World Health Organization. Dementia. 2021. https://www.who.int/ news-room/fact-sheets/detail/dementia\#: :text=Alzheimer's\%20dis ease $\% 20$ is\%20the\%20most,dependency\%20among\%20older\%20peo ple\%20globally. Accessed 07 Oct 2021.

2. Chávez-Gutiérrez L, Szaruga M. Mechanisms of neurodegeneration-insights from familial Alzheimer's disease. Semin Cell Dev Biol. 2020;105:75-85. https://doi.org/10.1016/j.semcdb.2020.03.005.

3. Weidner WS, Barbarino P. P4-443: the state of the art of dementia research new frontiers. Alzheimers Dement. 2019;15(7):P1473.

4. Bielschowsky M. Die Silberimpragnation der Axencylinder. New Centralbl. 1902;21:579-84

5. Van Broeckhoven C, Haan J, Bakker E, Hardy JA, Van Hul W, Wehnert A, et al. Amyloid beta protein precursor gene and hereditary cerebral hemorrhage with amyloidosis (Dutch). Science. 1990;248(4959):1120-2. https://doi.org/10.1126/science.1971458.

6. Vermunt $L$, Sikkes SAM, van den Hout A, Handels R, Bos I, van der Flier WM, et al. Duration of preclinical, prodromal, and dementia stages of Alzheimer's disease in relation to age, sex, and APOE genotype. Alzheimers Dement. 2019;15(7):888-98. https://doi.org/10.1016/j.jalz.2019.04. 001.

7. Bloom GS. Amyloid- $\beta$ and tau: the trigger and bullet in Alzheimer disease pathogenesis: the trigger and bullet in Alzheimer disease pathogenesis. JAMA Neurol. 2014;71(4):505-8. https://doi.org/10.1001/ jamaneurol.2013.5847.

8. Long JM, Holtzman DM. Alzheimer disease: an update on pathobiology and treatment strategies. Cell. 2019;179(2):312-39. https://doi.org/10. 1016/j.cell.2019.09.001.

9. Livingston G, Sommerlad A, Orgeta V, Costafreda SG, Huntley J, Ames $D$, et al. Dementia prevention, intervention, and care. Lancet. 2017:390(10113):2673-734.

10. Mullane K, Williams M. Alzheimer's disease beyond amyloid: Can the repetitive failures of amyloid-targeted therapeutics inform future approaches to dementia drug discovery? Biochem Pharmacol. 2020;177(113945): 113945

11. Bertram L, Tanzi RE. Alzheimer disease risk genes: 29 and counting. Nat Rev Neurol. 2019;15(4):191-2. https://doi.org/10.1038/ s41582-019-0158-4.

12. De Jonghe $C$, Zehr $C$, Yager D, Prada CM, Younkin S, Hendriks L, et al. Flemish and Dutch mutations in amyloid beta precursor protein have different effects on amyloid beta secretion. Neurobiol Dis. 1998:5(4):281-6. https://doi.org/10.1006/nbdi.1998.0202.

13. Uddin MS, Kabir MT, Mamun AA, Barreto GE, Rashid M, Perveen A, et al. Pharmacological approaches to mitigate neuroinflammation in Alzheimer's disease. Int Immunopharmacol. 2020;84(106479): 106479. https:// doi.org/10.1016/j.intimp.2020.106479.

14. Uddin MS, Mamun AA, Labu ZK, Hidalgo-Lanussa O, Barreto GE, Ashraf $\mathrm{GM}$, et al. Autophagic dysfunction in Alzheimer's disease: cellular and molecular mechanistic approaches to halt Alzheimer's pathogenesis. J Cell Physiol. 2019;234(6):8094-112. https://doi.org/10.1002/jcp.27588.

15. Kabir MT, Sufian MA, Uddin MS, Begum MM, Akhter S, Islam A, et al. NMDA receptor antagonists: repositioning of memantine as a multitargeting agent for Alzheimer's therapy. Curr Pharm Des. 2019;25(33):3506-18. https://doi.org/10.2174/13816128256661910111 02444.

16. Haapasalo A, Kovacs DM. The many substrates of presenilin/ $\mathrm{Y}$ secretase. J Alzheimers Dis. 2011;25(1):3-28. https://doi.org/10.3233/ JAD-2011-101065.

17. Wolfe MS. Unraveling the complexity of $\mathrm{y}$-secretase. Semin Cell Dev Biol. 2020;105:3-11. https://doi.org/10.1016/j.semcdb.2020.01.005.

18. Kopan R, llagan MXG. Gamma-secretase: proteasome of the membrane? Nat Rev Mol Cell Biol. 2004;5(6):499-504. https://doi.org/10. 1038/nrm1406.

19. Hitzenberger M, Götz A, Menig S, Brunschweiger B, Zacharias M, Scharnagl C. The dynamics of $\gamma$-secretase and its substrates. Semin Cell Dev Biol. 2020;105:86-101. https://doi.org/10.1016/j.semcdb.2020.04.008.

20. Glenner GG, Wong CW. Alzheimer's disease: initial report of the purification and characterization of a novel cerebrovascular amyloid protein. Biochem Biophys Res Commun. 1984;120(3):885-90. https://doi.org/10. 1016/s0006-291x(84)80190-4.
21. Kitaguchi N, Takahashi Y, Tokushima Y, Shiojiri S, Ito H. Novel precursor of Alzheimer's disease amyloid protein shows protease inhibitory activity. Nature. 1988;331(6156):530-2. https://doi.org/10.1038/331530a0.

22. Yoshikai S, Sasaki H, Doh-ura K, Furuya H, Sakaki Y. Genomic organization of the human amyloid beta-protein precursor gene. Gene. 1990;87(2):257-63. https://doi.org/10.1016/0378-1119(90)90310-n.

23. Wolfe MS. Dysfunctional $\gamma$-secretase in familial Alzheimer's disease. Neurochem Res. 2019;44(1):5-11. https://doi.org/10.1007/ s11064-018-2511-1.

24. Weidemann A, König G, Bunke D, Fischer P, Salbaum JM, Masters CL, et al. Identification, biogenesis, and localization of precursors of Alzheimer's disease A4 amyloid protein. Cell. 1989;57(1):115-26. https://doi. org/10.1016/0092-8674(89)90177-3.

25. Breen $\mathrm{KC}$, Bruce $\mathrm{M}$, Anderton $\mathrm{BH}$. Beta amyloid precursor protein mediates neuronal cell-cell and cell-surface adhesion. J Neurosci Res. 1991;28(1):90-100. https://doi.org/10.1002/jnr.490280109.

26. Kumar-Singh S. Nonfibrillar diffuse amyloid deposition due to a gamma42-secretase site mutation points to an essential role for N-truncated Abeta42 in Alzheimer's disease. Hum Mol Genet. 2000:9(18):2589-98. https://doi.org/10.1093/hmg/9.18.2589.

27. Lührs T, Ritter C, Adrian M, Riek-Loher D, Bohrmann B, Döbeli H, et al. 3D structure of Alzheimer's amyloid-beta(1-42) fibrils. Proc Natl Acad Sci U S A. 2005;102(48):17342-7. https://doi.org/10.1073/pnas.0506723102.

28. Zheng H, Jiang M, Trumbauer ME, Sirinathsinghji DJS, Hopkins R, Smith DW, et al. B-amyloid precursor protein-deficient mice show reactive gliosis and decreased locomotor activity. Cell. 1995;81(4):525-31. https://doi.org/10.1016/0092-8674(95)90073-x.

29. Müller W, Eckert A, Hartmann H, Förstl H. Free intracellular calcium in aging and Alzheimer's disease. In: Alzheimer Disease. Boston, MA: Birkhäuser Boston; 1994. p. 299-303. https://doi.org/10.1007/978-14615-8149-9 50

30. Luo L, Tully T, White K. Human amyloid precursor protein ameliorates behavioral deficit of flies deleted for Appl gene. Neuron. 1992;9(4):595605. https://doi.org/10.1016/0896-6273(92)90024-8.

31. Daigle I, Li C. apl-1, a Caenorhabditis elegans gene encoding a protein related to the human beta-amyloid protein precursor. Proc Natl Acad Sci U S A. 1993;90(24):12045-9. https://doi.org/10.1073/pnas.90.24. 12045.

32. Rovelet-Lecrux A, Hannequin D, Raux G, Le Meur N, Laquerrière A, Vital A, et al. APP locus duplication causes autosomal dominant early-onset Alzheimer disease with cerebral amyloid angiopathy. Nat Genet. 2006:38(1):24-6. https://doi.org/10.1038/ng1718.

33. Howlett DR, Jennings KH, Lee DC, Clark MS, Brown F, Wetzel R, et al. Aggregation state and neurotoxic properties of Alzheimer beta-amyloid peptide. Neurodegeneration. 1995;4(1):23-32. https://doi.org/10. 1006/neur.1995.0003.

34. Jarrett JT, Berger EP, Lansbury PT Jr. The carboxy terminus of the beta amyloid protein is critical for the seeding of amyloid formation: implications for the pathogenesis of Alzheimer's disease. Biochemistry. 1993;32(18):4693-7. https://doi.org/10.1021/bi00069a001.

35. Mantyh PW, Ghilardi JR, Rogers S, DeMaster E, Allen CJ, Stimson ER, et al. Aluminum, iron, and zinc ions promote aggregation of physiological concentrations of beta-amyloid peptide. J Neurochem. 1993;61(3):1171-4. https://doi.org/10.1111/j.1471-4159.1993.tb03639.x.

36. Bush Al, Pettingell WH, Multhaup G, Paradis Md, Vonsattel JP, Gusella JF, et al. Rapid induction of Alzheimer A beta amyloid formation by zinc. Science. 1994;265(5177):1464-7. https://doi.org/10.1126/science.80732 93.

37. Dyrks T, Dyrks E, Hartmann T, Masters C, Beyreuther K. Amyloidogenicity of beta A4 and beta A4-bearing amyloid protein precursor fragments by metal-catalyzed oxidation. J Biol Chem. 1992;267(25):18210-7.

38. Koh J-Y, Yang LL, Cotman CW. $\beta$-Amyloid protein increases the vulnerability of cultured cortical neurons to excitotoxic damage. Brain Res. 1990:533(2):315-20. https://doi.org/10.1016/0006-8993(90)91355-k.

39. Copani A, Koh J-Y, Cotman CW. B-Amyloid increases neuronal susceptibility to injufy by glucose deprivation. NeuroReport. 1991;2(12):763-5. https://doi.org/10.1097/00001756-199112000-00008.

40. Price JL, Davis PB, Morris JC, White DL. The distribution of tangles, plaques and related immunohistochemical markers in healthy aging and Alzheimer's disease. Neurobiol Aging. 1991;12(4):295-312. https:// doi.org/10.1016/0197-4580(91)90006-6. 
41. Ryan NS, Rossor MN. Correlating familial Alzheimer's disease gene mutations with clinical phenotype. Biomark Med. 2010;4(1):99-112. https://doi.org/10.2217/bmm.09.92.

42. Mullan M, Crawford F, Axelman K, Houlden H, Lilius L, Winblad B, et al. A pathogenic mutation for probable Alzheimer's disease in the APP gene at the N-terminus of beta-amyloid. Nat Genet. 1992;1(5):345-7. https:// doi.org/10.1038/ng0892-345.

43. Citron M, Oltersdorf T, Haass C, McConlogue L, Hung AY, Seubert P, et al. Mutation of the beta-amyloid precursor protein in familial Alzheimer's disease increases beta-protein production. Nature. 1992;360(6405):6724. https://doi.org/10.1038/360672a0.

44. Chen W-T, Hong C-J, Lin Y-T, Chang W-H, Huang H-T, Liao J-Y, et al. Amyloid-beta $(A \beta) D 7 H$ mutation increases oligomeric $A \beta 42$ and alters properties of A $\beta$-zinc/copper assemblies. PLoS ONE. 2012;7(4): e35807. https://doi.org/10.1371/journal.pone.0035807.

45. Kaden D, Harmeier A, Weise C, Munter LM, Althoff $V$, Rost BR, et al. Novel APP/A $\beta$ mutation $\mathrm{K} 16 \mathrm{~N}$ produces highly toxic heteromeric $A \beta$ oligomers: $\mathrm{A} \beta \mathrm{K} 16 \mathrm{~N}$ heteromeric oligomers are highly toxic. EMBO Mol Med. 2012;4(7):647-59. https://doi.org/10.1002/emmm.201200239.

46. Finckh U, Kuschel C, Anagnostouli M, Patsouris E, Pantes GV, Gatzonis $S$, et al. Novel mutations and repeated findings of mutations in familial Alzheimer disease. Neurogenetics. 2005;6(2):85-9. https://doi.org/10. 1007/s10048-005-0211-x.

47. Nilsberth C, Westlind-Danielsson A, Eckman CB, Condron MM, Axelman K, Forsell C, et al. The "Arctic" APP mutation (E693G) causes Alzheimer's disease by enhanced Abeta protofibril formation. Nat Neurosci. 2001;4(9):887-93. https://doi.org/10.1038/nn0901-887.

48. Kunkle BW, Grenier-Boley B, Sims R, Bis JC, Damotte V, Naj AC, et al. Genetic meta-analysis of diagnosed Alzheimer's disease identifies new risk loci and implicates $A \beta$, tau, immunity and lipid processing. Nat Genet. 2019;51(3):414-30. https://doi.org/10.1038/s41588-019-0358-2.

49. Czeh M, Gressens P, Kaindl AM. The yin and yang of microglia. Dev Neurosci. 2011;33(3-4):199-209. https://doi.org/10.1159/000328989.

50. Paresce DM, Ghosh RN, Maxfield FR. Microglial cells internalize aggregates of the Alzheimer's disease amyloid $\beta$-protein via a scavenger receptor. Neuron. 1996;17(3):553-65. https://doi.org/10.1016/s08966273(00)80187-7.

51. Lee CYD, Landreth GE. The role of microglia in amyloid clearance from the AD brain. J Neural Transm (Vienna). 2010;117(8):949-60. https://doi. org/10.1007/s00702-010-0433-4.

52. Hickman SE, Allison EK, El Khoury J. Microglial dysfunction and defective beta-amyloid clearance pathways in aging Alzheimer's disease mice. J Neurosci. 2008;28(33):8354-60. https://doi.org/10.1523/jneur osci.0616-08.2008.

53. Hickman SE, Kingery ND, Ohsumi TK, Borowsky ML, Wang L-C, Means TK, et al. The microglial sensome revealed by direct RNA sequencing. Nat Neurosci. 2013;16(12):1896-905. https://doi.org/10.1038/nn.3554.

54. Khachaturian ZS. 40 Years of Alzheimer's research failure: now what? MedpageToday. 2018. https://www.medpagetoday.com/neurology/ alzheimersdisease/75075. Accessed 7 Oct 2021

55. Blennow K, de Leon MJ, Zetterberg H. Alzheimer's disease. Lancet. 2006;368(9533):387-403. https://doi.org/10.1016/S0140-6736(06) 69113-7.

56. Xu Q, Bernardo A, Walker D, Kanegawa T, Mahley RW, Huang Y. Profile and regulation of apolipoprotein $E$ (ApoE) expression in the CNS in mice with targeting of green fluorescent protein gene to the ApoE locus. J Neurosci. 2006;26(19):4985-94. https://doi.org/10.1523/jneur osci.5476-05.2006.

57. Wahrle SE, Jiang H, Parsadanian M, Legleiter J, Han X, Fryer JD, et al. ABCA1 is required for normal central nervous system ApoE levels and for lipidation of astrocyte-secreted apoE. J Biol Chem. 2004:279(39):40987-93. https://doi.org/10.1074/jbc.m407963200.

58. Tokuda T, Calero M, Matsubara E, Vidal R, Kumar A, Permanne B, et al. Lipidation of apolipoprotein $\mathrm{E}$ influences its isoform-specific interaction with Alzheimer's amyloid $\beta$ peptides. Biochem J. 2000;348(2):359-65. https://doi.org/10.1042/bj3480359.

59. I wata N, Tsubuki S, Takaki Y, Watanabe K, Sekiguchi M, Hosoki E, et al. Identification of the major Abeta1-42-degrading catabolic pathway in brain parenchyma: suppression leads to biochemical and pathological deposition. Nat Med. 2000;6(2):143-50. https://doi.org/10.1038/72237.
60. Leissring MA, Farris W, Chang AY, Walsh DM, Wu X, Sun X, et al. Enhanced proteolysis of $\beta$-amyloid in APP transgenic mice prevents plaque formation, secondary pathology, and premature death. Neuron. 2003;40(6):1087-93. https://doi.org/10.1016/s0896-6273(03)00787-6.

61. Michaelson DM, Dolev I. P2-297 differential and isoform-specific effects of apolipoprotein E4 on the initiation of deposition and on the reversible dissolution and fibrillization of Ab in vivo. Neurobiol Aging. 2004;25:S317. https://doi.org/10.1016/s0197-4580(04)81042-x.

62. Rogers J, Strohmeyer R, Kovelowski CJ, Li R. Microglia and inflammatory mechanisms in the clearance of amyloid beta peptide. Glia. 2002;40(2):260-9. https://doi.org/10.1002/glia.10153.

63. Cao G, Bales KR, DeMattos RB, Paul SM. Liver X receptor-mediated gene regulation and cholesterol homeostasis in brain: relevance to Alzheimer's disease therapeutics. Curr Alzheimer Res. 2007:4(2):179-84. https://doi.org/10.2174/156720507780362173.

64. Hanseeuw BJ, Betensky RA, Jacobs HIL, Schultz AP, Sepulcre J, Becker JA, et al. Association of amyloid and tau with cognition in preclinical Alzheimer disease: a longitudinal study. JAMA Neurol. 2019;76(8):915-24. https://doi.org/10.1001/jamaneurol.2019.1424.

65. Naseri NN, Wang H, Guo J, Sharma M, Luo W. The complexity of tau in Alzheimer's disease. Neurosci Lett. 2019;705:183-94. https://doi.org/10. 1016/j.neulet.2019.04.022.

66. Bakota L, Ussif A, Jeserich G, Brandt R. Systemic and network functions of the microtubule-associated protein tau: implications for tau-based therapies. Mol Cell Neurosci. 2017;84:132-41. https://doi.org/10.1016/j. mcn.2017.03.003.

67. Lu Q, Wood JG. Functional studies of Alzheimer's disease tau protein. J Neurosci. 1993;13(2):508-15. https://doi.org/10.1523/jneurosci.13-0200508.1993.

68. Alonso AC, Zaidi T, Grundke-lqbal I, lqbal K. Role of abnormally phosphorylated tau in the breakdown of microtubules in Alzheimer disease. Proc Natl Acad Sci U S A. 1994;91(12):5562-6. https://doi.org/10.1073/ pnas.91.12.5562.

69. Duyckaerts C, Delatour B, Potier M-C. Classification and basic pathology of Alzheimer disease. Acta Neuropathol. 2009;118(1):5-36. https://doi. org/10.1007/s00401-009-0532-1.

70. Braak H, Braak E. Neuropathological stageing of Alzheimer-related changes. Acta Neuropathol. 1991;82(4):239-59. https://doi.org/10.1007/ bf00308809.

71. Braak H, Del Tredici K. The pathological process underlying Alzheimer's disease in individuals under thirty. Acta Neuropathol. 2011;121(2):17181. https://doi.org/10.1007/s00401-010-0789-4.

72. Wegmann S, Nicholls S, Takeda S, Fan Z, Hyman BT. Formation, release, and internalization of stable tau oligomers in cells. J Neurochem. 2016;139(6):1163-74. https://doi.org/10.1111/jnc.13866.

73. Merezhko M, Brunello CA, Yan X, Vihinen H, Jokitalo E, Uronen R-L, et al. Secretion of Tau via an unconventional non-vesicular mechanism. Cell Rep. 2018;25(8):2027-2035.e4. https://doi.org/10.1016/j.celrep.2018.10. 078.

74. Saman S, Kim W, Raya M, Visnick Y, Miro S, Saman S, et al. Exosomeassociated tau is secreted in tauopathy models and is selectively phosphorylated in cerebrospinal fluid in early Alzheimer disease. J Biol Chem. 2012;287(6):3842-9. https://doi.org/10.1074/jbc.m111.277061.

75. Simón D, García-García E, Royo F, Falcón-Pérez JM, Avila J. Proteostasis of tau. Tau overexpression results in its secretion via membrane vesicles. FEBS Lett. 2011;586(1):47-54. https://doi.org/10.1016/j.febslet.2011.11. 022.

76. Lee VM, Goedert M, Trojanowski JQ. Neurodegenerative tauopathies. Annu Rev Neurosci. 2001;24(1):1121-59. https://doi.org/10.1146/annur ev.neuro.24.1.1121.

77. Duka V, Lee J-H, Credle J, Wills J, Oaks A, Smolinsky C, et al. Identification of the sites of tau hyperphosphorylation and activation of tau kinases in synucleinopathies and Alzheimer's diseases. PLoS ONE. 2013;8(9): e75025. https://doi.org/10.1371/journal.pone.0075025.

78. Hampel H, Blennow K, Shaw LM, Hoessler YC, Zetterberg H, Trojanowski JQ. Total and phosphorylated tau protein as biological markers of Alzheimer's disease. Exp Gerontol. 2010;45(1):30-40. https://doi.org/ 10.1016/j.exger.2009.10.010.

79. Li QS, De Muynck L. Differentially expressed genes in Alzheimer's disease highlighting the roles of microglia genes including 
OLR1 and astrocyte gene CDK2AP1. Brain Behav Immun Health. 2021;13(100227): 100227. https://doi.org/10.1016/j.bbih.2021.100227.

80. Levy-Lahad E, Wasco W, Poorkaj P, Romano DM, Oshima J, Pettingell WH, et al. Candidate gene for the chromosome 1 familial Alzheimer's disease locus. Science. 1995;269(5226):973-7. https://doi.org/10. $1126 /$ science.7638622.

81. Saura CA, Choi S-Y, Beglopoulos V, Malkani S, Zhang D, Shankaranarayana Rao BS, et al. Loss of presenilin function causes impairments of memory and synaptic plasticity followed by age-dependent neurodegeneration. Neuron. 2004;42(1):23-36. https://doi.org/10. 1016/s0896-6273(04)00182-5.

82. Dumanchin C, Czech C, Campion D, Cuif MH, Poyot T, Martin C, et al. Presenilins interact with Rab11, a small GTPase involved in the regulation of vesicular transport. Hum Mol Genet. 1999;8(7):1263-9. https://doi.org/10.1093/hmg/8.7.1263.

83. LaFerla FM. Calcium dyshomeostasis and intracellular signalling in Alzheimer's disease. Nat Rev Neurosci. 2002;3(11):862-72. https://doi. org/10.1038/nrn960.

84. Mattson MP. ER calcium and Alzheimer's disease: in a state of flux. Sci Signal. 2010;3(114): e10. https://doi.org/10.1126/scisignal.3114pe10.

85. Murayama O, Tomita T, Nihonmatsu N, Murayama M, Sun X, Honda T, et al. Enhancement of amyloid $\beta 42$ secretion by 28 different presenilin 1 mutations of familial Alzheimer's disease. Neurosci Lett. 1999;265(1):61-3. https://doi.org/10.1016/s0304-3940(99)00187-1.

86. Thinakaran G, Borchelt DR, Lee MK, Slunt HH, Spitzer L, Kim G, et al. Endoproteolysis of presenilin 1 and accumulation of processed derivatives in vivo. Neuron. 1996;17(1):181-90. https://doi.org/10. 1016/s0896-6273(00)80291-3.

87. Capell A, Grünberg J, Pesold B, Diehlmann A, Citron M, Nixon R, et al. The proteolytic fragments of the Alzheimer's disease-associated presenilin-1 form heterodimers and occur as a 100-150-kDa molecular mass complex. J Biol Chem. 1998;273(6):3205-11. https://doi.org/10. 1074/jbc.273.6.3205.

88. Cruts M, Theuns J, Van Broeckhoven C. Locus-specific mutation databases for neurodegenerative brain diseases. Hum Mutat. 2012;33(9):1340-4. https://doi.org/10.1002/humu.22117.

89. Rossor MN, Fox NC, Beck J, Campbell TC, Collinge J. Incomplete penetrance of familial Alzheimer's disease in a pedigree with a novel presenilin-1 gene mutation. Lancet. 1996;347(9014):1560. https://doi. org/10.1016/s0140-6736(96)90715-1.

90. Sun L, Zhou R, Yang G, Shi Y. Analysis of 138 pathogenic mutations in presenilin-1 on the in vitro production of $A \beta 42$ and $A \beta 40$ peptides by $\gamma$-secretase. Proc Natl Acad Sci U S A. 2016;114(4):E476-85. https:// doi.org/10.1073/pnas.1618657114.

91. Tang N, Dehury B, Kepp KP. Computing the pathogenicity of Alzheimer's disease presenilin 1 mutations. J Chem Inf Model. 2019;59(2):858-70. https://doi.org/10.1021/acs.jcim.8b00896.

92. Jayadev S, Leverenz JB, Steinbart E, Stahl J, Klunk W, Yu C-E, et al. Alzheimer's disease phenotypes and genotypes associated with mutations in presenilin 2. Brain. 2010;133(Pt 4):1143-54. https://doi. org/10.1093/brain/awq033.

93. Somavarapu AK, Kepp KP. The dynamic mechanism of presenilin-1 function: Sensitive gate dynamics and loop unplugging control protein access. Neurobiol Dis. 2016;89:147-56. https://doi.org/10.1016/j. nbd.2016.02.008.

94. Duncan R, Song B, Koulen P. Presenilins as drug targets for Alzheimer's disease-recent insights from cell biology and electrophysiology as novel opportunities in drug development. Int J Mol Sci. 2018;19(6):1621. https://doi.org/10.3390/ijms19061621.

95. Reddy PH. Increased mitochondrial fission and neuronal dysfunction in Huntington's disease: implications for molecular inhibitors of excessive mitochondrial fission. Drug Discov Today. 2014;19(7):951-5. https://doi.org/10.1016/j.drudis.2014.03.020.

96. Harman D. Aging: a theory based on free radical and radiation chemistry. J Gerontol. 1956;11(3):298-300. https://doi.org/10.1093/geronj/11.3. 298.

97. Bhardwaj S, Kesari KK, Rachamalla M, Mani S, Ashraf GM, Jha SK, et al. CRISPR/Cas9 gene editing: new hope for Alzheimer's disease therapeutics. J Adv Res. 2021. https://doi.org/10.1016/j.jare.2021.07.001.

98. Van Giau V, Bagyinszky E, Yang YS, Youn YC, An SSA, Kim SY. Genetic analyses of early-onset Alzheimer's disease using next generation sequencing. Sci Rep. 2019;9(1):8368. https://doi.org/10.1038/ s41598-019-44848-2.

99. Prokopenko D, Morgan SL, Mullin K, Hofmann O, Chapman B, Kirchner $R$, et al. Whole-genome sequencing reveals new Alzheimer's diseaseassociated rare variants in loci related to synaptic function and neuronal development. Alzheimers Dement. 2021;17(9):1509-27. https:// doi.org/10.1002/alz.12319.

100. Kim H-R, Jung S-H, Kim J, Jang H, Kang SH, Hwangbo S, et al. Identifying novel genetic variants for brain amyloid deposition: a genome-wide association study in the Korean population. Alzheimers Res Ther. 2021;13(1):117. https://doi.org/10.1186/s13195-021-00854-z.

101. Park J-H, Park I, Youm EM, Lee S, Park J-H, Lee J, et al. Novel Alzheimer's disease risk variants identified based on whole-genome sequencing of APOE $\varepsilon 4$ carriers. Transl Psychiatry. 2021;1 1(1):296. https://doi.org/10. 1038/s41398-021-01412-9.

102. Xiaodong P, Murong Y, Jingjing X, Qi P, Menghao Y, Jing X, et al. Identification of novel gene variants in patients with Alzheimer's disease by whole exome sequencing. Ann Alzheimers Dement Care. 2020;4(1):001-4.

103. de Rojas I, Moreno-Grau S, Tesi N, Grenier-Boley B, Andrade V, Jansen IE, et al. Common variants in Alzheimer's disease and risk stratification by polygenic risk scores. Nat Commun. 2021;12(1):3417. https://doi.org/10. 1038/s41467-021-22491-8.

104. Lawingco T, Chaudhury S, Brookes KJ, Guetta-Baranes T, Guerreiro R, Bras J, et al. Genetic variants in glutamate-, $A \beta$-, and tau-related pathways determine polygenic risk for Alzheimer's disease. Neurobiol Aging. 2021;101:299.e13-299.e21. https://doi.org/10.1016/j.neurobiolaging. 2020.11.009.

105. Ou Y-N, Yang Y-X, Deng Y-T, Zhang C, Hu H, Wu B-S, et al. Identification of novel drug targets for Alzheimer's disease by integrating genetics and proteomes from brain and blood. Mol Psychiatry. 2021. https://doi. org/10.1038/s41380-021-01251-6.

106. He L, Loika Y, Park Y, Genotype Tissue Expression (GTEx) consortium, Bennett DA, Kellis M, et al. Exome-wide age-of-onset analysis reveals exonic variants in ERN1 and SPPL2C associated with Alzheimer's disease. Transl Psychiatry. 2021;11(1):146. https://doi.org/10.1038/ s41398-021-01263-4

107. Bossaerts L, Hens E, Hanseeuw B, Vandenberghe R, Cras P, De Deyn $\mathrm{PP}$, et al. Premature termination codon mutations in ABCA7 contribute to Alzheimer's disease risk in Belgian patients. Neurobiol Aging. 2021;106:307.e1-307.e7. https://doi.org/10.1016/j.neurobiolaging.2021. 04.023.

108. Lyssenko NN, Praticò D. ABCA7 and the altered lipidostasis hypothesis of Alzheimer's disease. Alzheimers Dement. 2021;17(2):164-74. https:// doi.org/10.1002/alz.12220

109. Aikawa T, Ren Y, Holm M-L, Asmann YW, Alam A, Fitzgerald ML, et al. ABCA7 regulates brain fatty acid metabolism during LPS-induced acute inflammation. Front Neurosci. 2021;15: 647974. https://doi.org/10.3389/ fnins.2021.647974.

110. Aikawa T, Ren Y, Yamazaki Y, Tachibana M, Johnson MR, Anderson CT, et al. ABCA7 haplodeficiency disturbs microglial immune responses in the mouse brain. Proc Natl Acad Sci U S A. 2019;1 16(47):23790-6. https://doi.org/10.1073/pnas.1908529116.

111. Liu Y, Thalamuthu A, Mather KA, Crawford J, Ulanova M, Wong MWK, et al. Plasma lipidome is dysregulated in Alzheimer's disease and is associated with disease risk genes. Transl Psychiatry. 2021;11(1):344. https://doi.org/10.1038/s41398-021-01362-2.

112. Hung C, Tuck E, Stubbs V, van der Lee SJ, Aalfs C, van Spaendonk R, et al. SORL1 deficiency in human excitatory neurons causes APPdependent defects in the endolysosome-autophagy network. Cell Rep. 2021;35(11): 109259. https://doi.org/10.1016/j.celrep.2021.109259.

113. Monti G, Kjolby M, Jensen AMG, Allen M, Reiche J, Møller PL, et al. Expression of an alternatively spliced variant of SORL1 in neuronal dendrites is decreased in patients with Alzheimer's disease. Acta Neuropathol Commun. 2021;9(1):43. https://doi.org/10.1186/ s40478-021-01140-7.

114. Andersen OM, Bøgh N, Landau AM, Pløen GG, Jensen AMG, Monti G, et al. In vivo evidence that SORL1, encoding the endosomal recycling receptor SORLA, can function as a causal gene in Alzheimer's Disease. bioRxiv. 2021. https://doi.org/10.1101/2021.07.13.452149. 
115. Mishra S, Knupp A, Szabo M, Kinoshita C, Hailey DW, Wang Y, et al. The Alzheimer's gene SORL1 is a key regulator of endosomal recycling in human neurons. bioRxiv. 2021. https://doi.org/10.1101/2021.07.26. 453861.

116. Cuccaro ML, Carney RM, Zhang Y, Bohm C, Kunkle BW, Vardarajan BN, et al. SORL1 mutations in early- and late-onset Alzheimer disease. Neurol Genet. 2016;2(6): e116. https://doi.org/10.1212/NXG.0000000000 000116.

117. Zhou Y, Song WM, Andhey PS, Swain A, Levy T, Miller KR, et al. Human and mouse single-nucleus transcriptomics reveal TREM2-dependent and TREM2-independent cellular responses in Alzheimer's disease. Nat Med. 2020;26(1):131-42. https://doi.org/10.1038/s41591-019-0695-9.

118. Wang S, Mustafa M, Yuede CM, Salazar SV, Kong P, Long H, et al. Antihuman TREM2 induces microglia proliferation and reduces pathology in an Alzheimer's disease model. J Exp Med. 2020. https://doi.org/10. 1084/jem.20200785.

119. Ellwanger DC, Wang S, Brioschi S, Shao Z, Green L, Case R, et al. Prior activation state shapes the microglia response to antihuman TREM2 in a mouse model of Alzheimer's disease. Proc Natl Acad Sci U S A. 2021;118(3): e2017742118. https://doi.org/10.1073/pnas.2017742118.

120. McQuade A, Kang YJ, Hasselmann J, Jairaman A, Sotelo A, Coburn M, et al. Gene expression and functional deficits underlie TREM2-knockout microglia responses in human models of Alzheimer's disease. Nat Commun. 2020;11(1):5370. https://doi.org/10.1038/s41467-020-19227-5.

121. Parhizkar S, Arzberger T, Brendel M, Kleinberger G, Deussing M, Focke $C$, et al. Loss of TREM2 function increases amyloid seeding but reduces plaque-associated ApoE. Nat Neurosci. 2019;22(2):191-204. https://doi. org/10.1038/s41593-018-0296-9.

122. Li Z, Shue F, Zhao N, Shinohara M, Bu G. APOE2: protective mechanism and therapeutic implications for Alzheimer's disease. Mol Neurodegener. 2020;15(1):63. https://doi.org/10.1186/s13024-020-00413-4.

123. Reiman EM, Arboleda-Velasquez JF, Quiroz YT, Huentelman MJ, Beach TG, Caselli RJ, et al. Exceptionally low likelihood of Alzheimer's dementia in APOE2 homozygotes from a 5,000-person neuropathological study. Nat Commun. 2020;11(1):667. https://doi.org/10.1038/ s41467-019-14279-8.

124. Shinohara M, Kanekiyo T, Tachibana M, Kurti A, Shinohara M, Fu Y, et al. APOE2 is associated with longevity independent of Alzheimer's disease. Elife. 2020. https://doi.org/10.7554/eLife.62199.

125. Salvadó G, Grothe MJ, Groot C, Moscoso A, Schöll M, Gispert JD, et al. Differential associations of APOE- 22 and APOE- $\varepsilon 4$ alleles with PETmeasured amyloid- $\beta$ and tau deposition in older individuals without dementia. Eur J Nucl Med Mol Imaging. 2021;48(7):2212-24. https://doi. org/10.1007/s00259-021-05192-8.

126. Lefterov I, Wolfe CM, Fitz NF, Nam KN, Letronne F, Biedrzycki RJ, et al. APOE2 orchestrated differences in transcriptomic and lipidomic profiles of postmortem AD brain. Alzheimers Res Therapy. 2019;11(1):113. https://doi.org/10.1186/s13195-019-0558-0.

127. Scheltens $P$, De Strooper B, Kivipelto M, Holstege $H$, Chételat $G$, Teunissen CE, et al. Alzheimer's disease. Lancet. 2021;397(10284):1577-90. https://doi.org/10.1016/S0140-6736(20)32205-4.

128. Jonsson T, Atwal JK, Steinberg S, Snaedal J, Jonsson PV, Bjornsson S, et al. A mutation in APP protects against Alzheimer's disease and agerelated cognitive decline. Nature. 2012;488(7409):96-9. https://doi.org/ 10.1038/nature11283.

129. Sims R, van der Lee SJ, Naj AC, Bellenguez C, Badarinarayan N, Jakobsdottir J, et al. Rare coding variants in PLCG2, ABI3, and TREM2 implicate microglial-mediated innate immunity in Alzheimer's disease. Nat Genet. 2017;49(9):1373-84. https://doi.org/10.1038/ng.3916.

130. Hansen DV, Hanson JE, Sheng M. Microglia in Alzheimer's disease. J Cell Biol. 2018;217(2):459-72. https://doi.org/10.1083/jcb.201709069.

131. Yeh FL, Wang Y, Tom I, Gonzalez LC, Sheng M. TREM2 binds to apolipoproteins, including APOE and CLU/APOJ, and thereby facilitates uptake of amyloid-beta by microglia. Neuron. 2016;91(2):328-40. https://doi. org/10.1016/j.neuron.2016.06.015.

132. Lemprière $\mathrm{S}$. Genome-wide association study identifies new risk loci for Alzheimer disease. Nat Rev Neurol. 2021. https://doi.org/10.1038/ s41582-021-00575-9.

133. Wightman DP, Jansen IE, Savage JE, Shadrin AA, Bahrami S, Holland D, et al. A genome-wide association study with 1,126,563 individuals identifies new risk loci for Alzheimer's disease. Nat Genet. 2021;53(9):1276-82. https://doi.org/10.1101/2020.11.20.20235275.

134. Bruni AC, Bernardi L, Gabelli C. From beta amyloid to altered proteostasis in Alzheimer's disease. Ageing Res Rev. 2020;64(101126): 101126. https://doi.org/10.1016/j.arr.2020.101126.

\section{Publisher's Note}

Springer Nature remains neutral with regard to jurisdictional claims in published maps and institutional affiliations.

\section{Submit your manuscript to a SpringerOpen ${ }^{\circ}$ journal and benefit from:}

- Convenient online submission

- Rigorous peer review

- Open access: articles freely available online

- High visibility within the field

- Retaining the copyright to your article

Submit your next manuscript at $\boldsymbol{\nabla}$ springeropen.com 